\title{
A Note On The Determinants Of Inter-Metropolitan Migration
}

\author{
Richard J. Cebula* and Margaret N. Davis
}

Researchers have long been interested in the determinants of human migration. Most empirical studies of migrant behavior regress migration rates against a variety of economic variables, such as unemployment rates, per capita income, and median income. More recently, the trend in the literature has been to include in these regressions various quality of life variables, such as climate, pollution, and congestion. However, except for Rabianski (5), no effort has been made in the empirical migration literature to account for geographic living - cost differentials (although their potential importance has been noted; see e.g., Cebula (1, Ch. 4) and Riew (6)). In the United States, such differentials are relatively large; hence, ignoring geographic living-cost differentials introduces the very distinct possibility of "money illusion" on the part of migrants.

The objective of this note is to examine empirically the impact on geographic mobility of explicitly including geographic living costs in the migration decision calculus. This study is directed toward an analysis of migration patterns in the United States. Specifically, the study examines net migration over the 1960-1970 period to some 36 Standard Metropolitan Statistical Areas (SMSA's) in the United States for which adequate living-cost data are available. ${ }^{1}$

The most basic problem this note must address is how precisely to introduce living costs into a migration model. When Rabianski (5) addressed this problem in his analysis of migration patterns in the United States, he chose to use price indices to deflate nominal earnings into real earnings. Rabianski then compared the results of two migration regressions. One regression included nominal earnings, as well as other explanatory variables; the second regression differed from the first only by its inclusion of real rather than nominal earnings.

His comparison of the two regressions led him to conclude that:

"First, the sign of the coefficient for the earnings ratio in both the nominal and the real earnings model is as expected from theory. Second, in both models, the $T$-ratios for the earnings ratios are significantly different from zero at the .01 level of significance. However, the inclusion of the inter-regional cost-of-living deflator did not significantly improve the model based upon nominal earnings." (5, pp. 191-192).

In view of the fact that the "deflator approach" did not significantly influence the regression results, this note adopts an alternative approach

*Professor of Economics, Emory University, Atlanta, Georgia 30322 
to the problem; in particular, it examines the migration impact of geographic living-cost differentials by including the cost of living as a completely separate explanatory variable.

The basic model to be examined here is the following:

$$
\text { (1) } \mathrm{Mi}=\mathrm{a}_{0}+\mathrm{a}_{1} \mathrm{Yi}+\mathrm{a}_{2} \mathrm{Ui}+\mathrm{a}_{3} \mathrm{DDi}+\mathrm{a}_{4}
$$

where $\mathrm{Mi}=$ volume of net in-migration to SMSAi, 1960-1970, expressed as a percentage of SMSAi's 1960 population

$\mathrm{a}_{0}=$ constant

$\mathrm{Yi}=1959$ median family income in SMSAi

$\mathrm{Ui}=1960$ average unemployment rate in SMSAi

$\mathrm{DDi}=$ annual degree days, $65^{\circ}$ base, in SMSAi (based on the period 1931-1960)

$\mathrm{a}_{4}=$ error term

This model, which contains "standard" migration-determining variables, is expected, on the basis of studies such as Gallaway and Cebula (2), Liu (3), Pack (4), and Rabianski (5), to yield the following signs for the coefficients :

(2) $\mathrm{a}_{1}>0, \mathrm{a}_{2}<0, \mathrm{a}_{3}<0$

The OLS estimate of equation (1) is given by:

$$
\begin{aligned}
\text { (3) } \mathrm{MI} & =+26.71205+\underset{(+0.04)}{0.00008} \mathrm{Yi}-\underset{(-2.95)}{2.74725 \mathrm{Ui}-\underset{(-3.34)}{0.00201} \mathrm{DDi}} \\
\mathrm{DF} & =32, \overline{\mathrm{R}}^{2}=.32
\end{aligned}
$$

where terms in parentheses are t-values.

In regression equation (3), all three of the estimated coefficients have the expected signs. Two of the estimated coefficients $\left(a_{2}\right.$ and $\left.a_{3}\right)$ are statistically significant at beyond the .01 level; in fact, only the coefficient for income $\left(a_{1}\right)$ fails to be significant at an acceptable (i.e., .05) level.

In order to appreciate the potential migration role of living costs, we next estimate the following regression:

$$
\text { (4) } \mathrm{Mi}=\mathrm{b}_{0}+\mathrm{b}_{1} \mathrm{Yi}+\mathrm{b}_{2} \mathrm{Ui}+\mathrm{b}_{3} \mathrm{DDi}+\mathrm{b}_{4} \mathrm{Pi}+\mathrm{b}_{5}
$$

where $\mathrm{b}_{0}=$ constant

$\mathrm{Pi}=$ the average cost of living for a four-person family in

SMSAi, 1966, expressed in current United States dollars ${ }^{2}$

$\mathrm{b}_{5}=$ error term

The model in equation (4) differs from that in equation (1) solely by its inclusion of the separate living-cost variable. Presumably, the higher the cost of living in an area, the less attractive it should be to migrants, ceteris paribus; hence, we expect the coefficient for variable $\mathrm{Pi}$ to be negative: 
(5) $\mathrm{b}_{4}<0$

The OLS estimate of equation (4) is given by:

$$
\begin{array}{cc}
\text { (6) } \mathrm{Mi}= & +55.67774+\underset{(+1.73)}{0.00342} \mathrm{Yi}-\underset{(-3.24)}{2.87971 \mathrm{Ui}-} \\
0.00206 & \mathrm{DDi}-0.00536 \mathrm{Pi} \\
(-3.58) & (-2.06) \\
\mathrm{DF} & =31, \overline{\mathrm{R}}^{2}=.41
\end{array}
$$

In regression (6), all of the estimated coefficients have the expected signs. In addition, all of the estimated coefficients in the equation are statistically significant at the .05 level or beyond.

Estimations (3) and (6) are different in a number of important respects. First, the coefficient for income is not significant at even the .10 level in equation (3), whereas it is significant at the .05 level in equation (6). Second, equation (6) contains an additional variable, the cost of living, which is statistically significant at about the .02 level. Finally, equation (6) has a considerably higher $\bar{R}^{2}$ value than does equation $(3)-.41$ versus .32 .

In sum, then, contrasting results (3) and (6) implies that: (a) the cost of living is an important determinant of geographic mobility in the United States $;^{3}$ thus, migrants in the United States apparently are not strictly subject to "money illusion"; and (b) omission of the living cost variable from migration analyses may constitute a serious specification error, i.e., "omitted variable" error.

This note has argued that migration behavior should be, assuming the absence of "money illusion," sensitive to geographic living-cost differentials. An earlier study by Rabianski (5), which deflated nominal earnings into real earnings, found living costs to have no impact on migration in the United States. However, the present study, which introduces geographic living costs into the migration regression as a separate variable, yields results which strongly imply that, ceteris paribus, migrants do in fact prefer areas with lower living costs. Moreover, estimations of more than a dozen different variations on the model in this paper have yielded the same basic results. ${ }^{4}$ Hence, future empirical migration research should, whenever possible (i.e., whenever adequate data are available), take geographic living-cost differentials expressly into account. Failure to do so will likely result in a misspecified model and in questionable empirical results.

\section{FOOTNOTES}

'The SMSA's studied were Atlanta, (;A; Austin, TX: Bakersfield. C:A. Baltimore. MD; Baton Rouge. I.A; Buffalo, NY; Cedar Rapids, IA; Champaign. II; Chicago, Il.; Cincinnati. OH; Cleveland, OH; Dallas, TX; Dayton, ()H; Denver, C.O; Detroit, MI; Durham, NC; Greenbay, WI; Honolulu. $\mathrm{HI}$; Houston. TX; Indianapolis, IN; Kansas (ity, MO); Ios Angeles, (.A; I ancaster, PA; Milwaukee, WI ; Nashville. TN; Orlando, FI.; Philadelphia, PA; Pittsburgh, PA; St. Louis, MO; San
Diego, (A); San Francisco, (:A; Seattle. W'A; Washington. DC; Wichita, KS; New York, NY; and Minneapolis, MN. The data source was the Statistical Abstract of the United States: 1968. These geographically comparable living cost data indicate the annual cost of a moderate living standard for a four-person family. The data source for the other variables in this study were The County and City Data Book: 1962. Table 3, and various issues of the Statistical Abstract of the United Stales. 
'In order to insure adequate sample size, data on family budget costs were collected for the year 1966 . Prior to 1966, such data are available for only 20 metropolitan areas.
${ }^{3}$ This contrasts to the results in Rabianski (5), where gross rather than net migration is examined.

These results will be supplied upon written request.

\section{REFERENCES}

1. Cebula, R. J., The Determinants of Human Migration, Lexington, Mass.: D. C. Heath and Company, 1979

2. Gallaway, L. E. and Cebula, R. J., "Differentials and Indeterminacy in Wage Rate Analysis: An Empirical Note," Industrial and Labor Relations Review 26 (April 1973): 991-995.

3. Liu, B. C., "Differential Net Migration Rates and the Quality of Life" Review of Economics and Statistics 57 (August 1975): 329-337.
4. Pack, J. R., "Determinants of Migration to Central Cities," Journal of Regional Science 13 (August 1973): 249-260.

5. Rabianski, J. S., "Real Earnings and Human Migration," Journal of Human Resources 6 (Spring 1971): 185-192.

6. Riew, J., "Migration and Public Policy," Journal of Regional Science 13 (April 1973): 65-76. 